Article

\title{
Analysis of Operational Changes of Tarbela Reservoir to Improve the Water Supply, Hydropower Generation, and Flood Control Objectives
}

\author{
Ahmed Rafique ${ }^{1, *}$, Steven Burian ${ }^{1}$, Daniyal Hassan ${ }^{1}\left[\right.$ and Rakhshinda Bano ${ }^{2}(\mathbb{C}$ \\ 1 Department of Civil and Environmental Engineering, University of Utah, Salt Lake City, UT 84112, USA; \\ steve.burian@utah.edu (S.B.); u6010713@umail.utah.edu (D.H.) \\ 2 U.S.-Pakistan Center for Advanced Studies in Water, Mehran University of Engineering and Technology, \\ Jamshoro City, Sindh 76062, Pakistan; rakshikarim@gmail.com \\ * Correspondence: ahmed.rafique@utah.edu
}

Received: 30 August 2020; Accepted: 14 September 2020; Published: 22 September 2020

\begin{abstract}
In this study, a model was created with the Water Evaluation and Planning (WEAP) System and used to explore the benefits of altering the operations of Tarbela Dam in terms of reliability, resilience, and vulnerability (RRV) for the three objectives of irrigation supply, hydropower generation, and flood control. Sensitivity analysis and logical reasoning with operators identified a feasible operational rule curve for testing using the integrated performance analysis. The reservoir performance for the altered operations was compared to the baseline performance following current operations for both historical and projected future climate and water demand conditions. Key simulation results show that the altered operations strategy tested under historical climate and water demand conditions would increase RRV by $17 \%, 67 \%$, and $7 \%$, respectively, for the water supply objective and $34 \%, 346 \%$, and $22 \%$, respectively, for hydropower generation. For projected future conditions, the proposed operations strategy would increase RRV by $7 \%, 219 \%$, and $11 \%$, respectively, for water supply and $19 \%, 136 \%$, and $13 \%$ for hydropower generation. Synthesis of the results suggests significant benefits for reliability and resilience of water supply and hydropower are possible with slight operational adjustments. Overall, the integrated performance analysis supports the need to develop an optimized operations rule for Tarbela to adapt to projected climate and demand scenarios.
\end{abstract}

Keywords: reservoir management; reservoir performance; water management modeling; climate change; water resources planning

\section{Introduction}

Water management has become more complex with human population growth; the emergence of broader performance objectives; and the increase in uncertainty of water availability, energy demand, and flood risk [1-3]. In South Asia, Pakistan is facing grave challenges of increasing population, intensifying precipitation extremes, and broadened expectations for water system performance $[4,5]$. Once a water-abundant country, Pakistan is now a water-stressed country and is estimated to become water-scarce by 2025, potentially threatening the hydropower and agriculture sector [6,7]. Additionally, floods and droughts pose a significant threat to agriculture and hydropower generation [8,9].

Given Pakistan's water challenges, large multi-purpose reservoirs such as Tarbela Reservoir constitute a vital component of the country's water resource infrastructure $[10,11]$. The Tarbela Reservoir on the Indus River serves multiple purposes, most importantly irrigation supply, hydropower generation, and flood control [12]. The post-Tarbela period has yielded significant economic 
benefits for Pakistan by increasing the irrigation command area, enhancing the hydropower capacity, and attenuating flood peaks during the flood season [13].

Although Tarbela Reservoir was designed to serve multiple purposes, the current operations and management practices are biased towards a solitary objective of meeting irrigation supply [14]. This implies that hydropower generation and flood control objectives are neglected in the current operations compromising the potential broader performance. According to the Pakistan Water \& Power Development Authority (WAPDA), 70\% of water discharge is through the spillways (uncontrolled releases), which do not generate hydropower [14]. This situation is alarming as the energy needs of Pakistan are increasing by $7.9 \%$ annually (currently, Tarbela contributes to $30 \%$ of the country's hydropower). Similarly, these uncontrolled releases (which occur when flow in the Indus is greater than $11,326 \mathrm{~m}^{3} / \mathrm{s}$ ) have resulted in 13 flood events causing significant damage to the agriculture sector.

To meet its objectives, Tarbela Reservoir is operated following a rule curve that defines the desired water surface elevation (and thus stored water volume) of the reservoir at a given time (Figure 1). Based upon the operations, the rule curve has three characteristic components: (i) falling limb (September-May), (ii) minimum level period (May-June), and (iii) rising limb (July-August). Releases from the reservoir as depicted by the falling limb and minimum level period are based on irrigation demands, also known as Kirmani demands in Pakistan, as shown in Figure 2 [15]. However, this irrigation demand pattern and the corresponding release pattern from the rule curve present a misleading case of irrigation demands being the highest for June-August. Recent studies have shown that the current and future crop water demand pattern, represented by crop evapotranspiration (ETo), is higher in the months of April-June (Table 1) [16,17]. Moreover, the available head in the minimum level period and the rising limb does not correspond to the high hydropower demand for those months. Figure 2 shows that the hydropower demand is highest for the months of June-August, but the rule curve maintains a low reservoir level in June and July, compromising its hydropower generation.

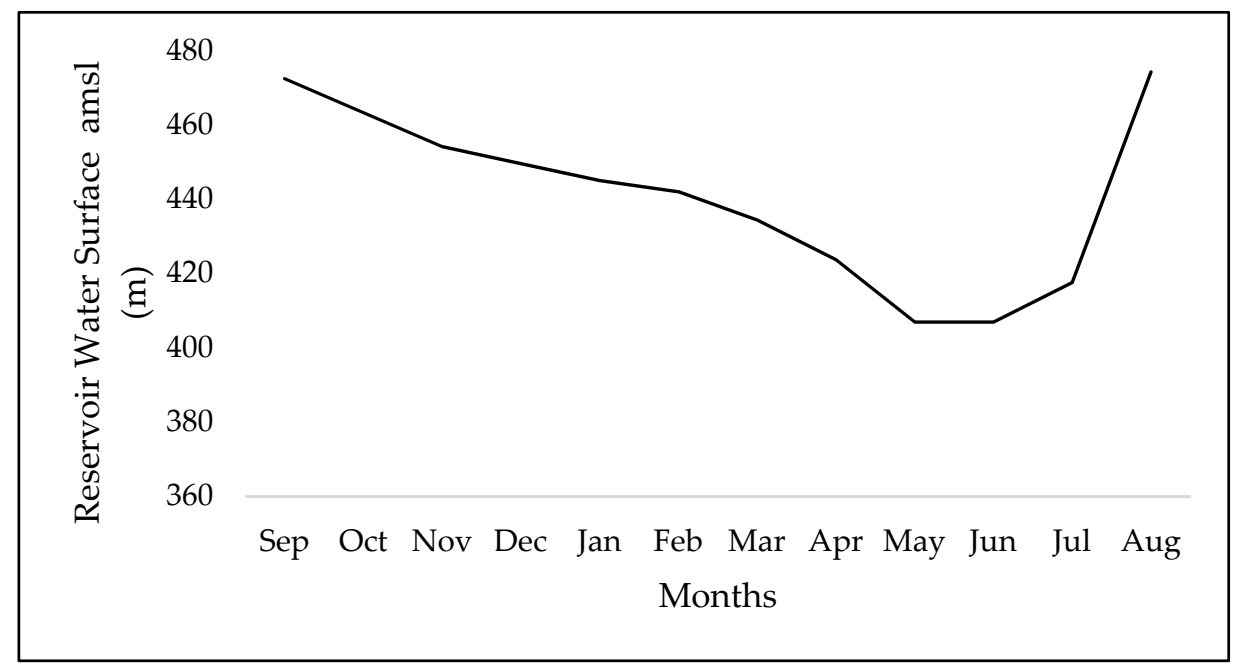

Figure 1. Current rule curve for the Tarbela Reservoir on a daily time scale.

Table 1. Monthly crop evapotranspiration (ETo) in mm for Northern Pakistan.

\begin{tabular}{ccccccccccccc}
\hline Scenario & Jan & Feb & Mar & Apr & May & Jun & Jul & Aug & Sep & Oct & Nov & Dec \\
\hline Current & 68 & 84 & 130 & 173 & 218 & 215 & 194 & 177 & 155 & 124 & 83 & 64 \\
$1{ }^{\circ}$ C Rise & 69 & 85 & 131 & 175 & 219 & 216 & 197 & 178 & 156 & 126 & 84 & 65 \\
$2{ }^{\circ}$ C Rise & 71 & 87 & 133 & 178 & 224 & 221 & 200 & 182 & 160 & 129 & 86 & 67 \\
$3^{\circ}$ C Rise & 76 & 93 & 141 & 186 & 232 & 229 & 207 & 189 & 166 & 134 & 90 & 72 \\
\hline
\end{tabular}




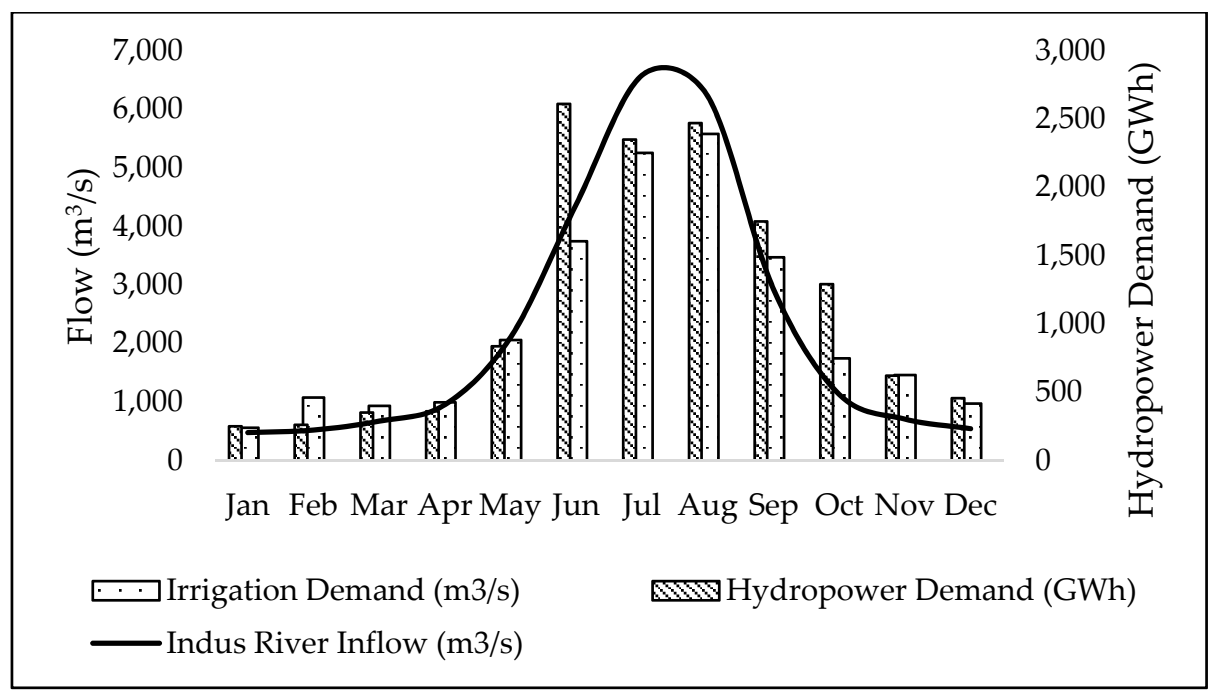

Figure 2. Mean monthly inflows, irrigation, and hydropower demand.

Part of the problem is the reliance of Tarbela Reservoir operational planning on the single criterion of irrigation supply reliability. The use of a single performance criterion (typically reliability of irrigation supply) is common for reservoir operations around the world but is known to be limited in describing the strengths and weaknesses of the reservoir operations [18,19]. Improvement in operational performance is likely feasible if decisions can consider multiple criteria, and in particular, reliability, resilience, and vulnerability (RRV) [20,21].

Complicating matters, the Tarbela Reservoir is located in a region vulnerable to climate change due to projected variability in precipitation and snowmelt [22-24]. Previous research has indicated that an extreme climate change scenario could shift the timing of peak inflows to an earlier month [25]. This implies that the filling of the reservoir (rising limb) should start early to attenuate the flood peak and store the flood volume. Furthermore, research suggests that climate change affects the crop sowing pattern with early sowing, resulting in higher yield [26]. This change in the sowing pattern would require early irrigation releases from the reservoir and corresponding low storage volume for the falling limb. Along with the above mentioned operational stressors, climate change imparts further stress on the physical aspects of Tarbela Reservoir due to a low storage coefficient of 0.11 (ratio of live storage to mean annual inflows) and a high draft ratio of 0.97 (ratio of annual demands to the mean annual inflows) [14]. The low storage coefficient compromises the Tarbela Reservoir's ability to regulate extreme hydrological flow variability.

The efforts to develop an integrated decision support tool for assessing the Indus basin system performance were initiated in 1980s by WAPDA and introduced an Indus Basin Model (IBM) and Indus Basin Model Revised (IBMR) for decision-making in water resource investments [7]. However, the IBM aims to maximize the net economic benefits from agriculture and does not consider water coverage, reliability, resilience, vulnerability, and demand priorities (agricultural and flood-control). Furthermore, previous studies on Tarbela have focused mainly on rule curve optimization methodologies to improve the performance of the reservoir. For instance, Rashid et al., (2017) used a genetic algorithm for multi-objective optimization to reduce irrigation deficit in Tarbela [27]. This study proposed a low reservoir level (as compared to the current rule curve) for all months except August and September. Although this approach managed to reduce irrigation deficit by a small amount $\left(<1.23 \mathrm{~km}^{3}\right)$, no improvement was achieved for hydropower generation and flood damage reduction. A similar irrigation-centric rule curve optimization approach was employed by Khan et al., (2012), which recommended further reducing the minimum reservoir level from 417 to $396 \mathrm{~m}$ [15]. The underlying argument behind this approach was that the rule curves resulting from the minimization of irrigation deficits should be preferred, since Tarbela was developed to maximize 
irrigation benefits. These studies have strived to improve the performance of the Tarbela Reservoir, yet they have failed to achieve a suitable tradeoff among the multiple objectives of irrigation supply, hydropower generation, and flood control by focusing solely on irrigation benefits.

This study was based on a minimalistic approach with a focus towards a generic improvement of the reservoir operation by strategic shifting of the minimum water level in the reservoir rather than developing an optimization algorithm. This approach has been widely used to solve complex problems typical of water resource systems requiring a design strategy based on simulation [21,28,29]. For Tarbela Reservoir, this approach was undertaken after extensive deliberations with all the relevant stakeholders (August 2015 to December 2018) to ensure its analytical simplicity, implementation, relevance to the anticipated impacts of future changes in irrigation demand, hydropower generation, climate, and tradeoffs between operating objectives.

The goal of this research was to use an integrated analysis of multiple objectives to prove the feasibility of improving the performance of the Tarbela Reservoir by altering the current rule curve. The reservoir was modeled in a Water Evaluation and Planning (WEAP) model, using a historical 39 years' streamflow time series for the Indus River along with climate data, irrigation, energy demands and the hydraulic parameters for Tarbela Reservoir. The objective was to explore the effect of alternate operations on the reliability of water supply for irrigation and hydropower and to identify the alternate operation resulting in the highest reliability. Using the proposed rule curve (which resulted in the highest system reliability) and a multicriteria evaluation approach, the performance of the reservoir was evaluated under historical and future conditions. The future conditions were determined using a stress test that explores a range of future possibilities based on historical conditions. Based on preliminary considerations, it was hypothesized that shifting the targeted low storage volumes in the reservoir earlier in the calendar year would lead to improved RRV for the three target objectives of irrigation supply, hydropower generation, and flood control.

\subsection{Description of Study Area}

\subsubsection{Indus River}

The Indus River emerges from the Tibetan Plateau, enters the north-eastern part of Pakistan, flows through the dry alluvial plains of Punjab and Sindh, and drains into the Arabian Sea. The catchment area of the Indus Basin contributing to the Tarbela Reservoir (the only controlling structure on the Upper Indus River) is $102,435 \mathrm{~km}^{2}[30,31]$. The mean annual flow of the Indus at Besham Qila, located $80 \mathrm{~km}$ upstream of Tarbela Reservoir, is $2336 \mathrm{~m}^{3} / \mathrm{s}$ [14]. The river flow is highly variable with a standard deviation of $2471 \mathrm{~m}^{3} / \mathrm{s}$ and recorded low and high flows of $252 \mathrm{~m}^{3} / \mathrm{s}$ (7 March 2002) and $20,100 \mathrm{~m}^{3} / \mathrm{s}$ (30 July 2010), respectively [14]. The historical mean monthly inflow shows the typical high intra-annual variation, with about $84 \%$ of the annual inflow arriving from May to September, as shown in Figure 2 [32].

\subsubsection{Tarbela Dam and Reservoir}

The Tarbela Dam (Latitude: $34^{\circ} 05^{\prime} 23^{\prime \prime}$ N, Longitude: $72^{\circ} 41^{\prime} 54^{\prime \prime}$ E), located in the Swabi district of Khyber Pakhtunkhwa province, Pakistan, was constructed in 1976 on the Indus River as an outcome of the Indus Waters Treaty (IWT) signed between Pakistan and India in 1960 (Figure 3). The IWT had provisions to construct three storage reservoirs, namely Tarbela, Mangla, and Chashma, six barrages, and eight link canals to mitigate the effect of the loss of water due to the restriction on the flows of the rivers in Eastern Pakistan [33]. Besides the primary function of mitigating the effect of loss of water from the eastern rivers and providing a firm base for the development of the irrigation system, a subsidiary goal of hydropower generation was also introduced during the planning phase. The initial design of Tarbela Dam had no provisions for flood control. Flood regulation became an incidental aspect of Tarbela, providing limited flow regulation during the flooding season from July through August. 


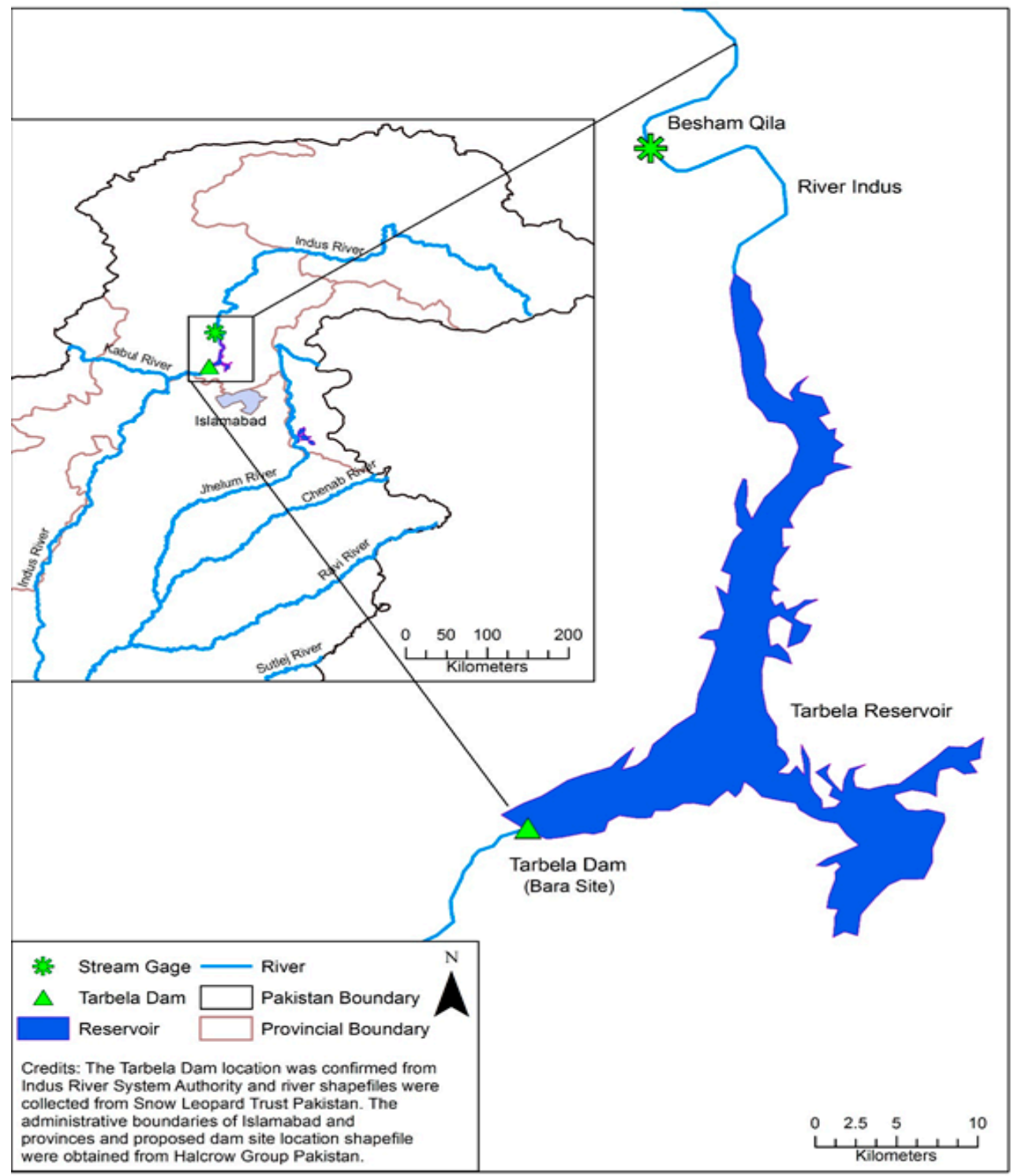

Figure 3. Location map of Tarbela Dam and Reservoir.

\subsubsection{Current Reservoir Operations of Tarbela}

Tarbela is a large multipurpose reservoir, the operational rules of which are now set according to the irrigation requirements of the provinces. From 1976 to 1993, the lack of a water-sharing agreement between the provinces led to ad hoc operations of the Tarbela Reservoir. In 1991, the provinces signed a formal accord, which resulted in the creation of the Indus River System Authority (IRSA) in 1993. The IRSA is now the designated body responsible for water allocation among the provinces based on agreed indicators of the provincial allocations, which are dependent on the average river flows. The indents (water requests) submitted by the provinces form the basis of the outflows from the reservoir, which over the operational period of Tarbela resulted in the development of the rule curve. The rule curve developed by WAPDA (Figure 1) shows that the reservoir should be lowered to the minimum level of $396 \mathrm{~m}$ above mean sea level (amsl) by the middle of May until the 20th of June to maximize releases for irrigation demand. The maximum level of $472 \mathrm{~m}$ amsl is the target for mid-August after attenuating the high flood peaks in July and early August. The filling should be at an average rate of $2.8 \mathrm{~m} /$ day up to $460 \mathrm{~m}$ amsl and $0.3 \mathrm{~m} /$ day from 460 to $472 \mathrm{~m}$ amsl. The filling rates were established by considering the structural integrity and safety of Tarbela Dam. 


\section{Materials and Methods}

This study was divided into three parts (Figure 4). First, a computer model was created using the Water Evaluation and Planning (WEAP) system. This model was verified using observed data. Second, the WEAP model was used to iterate through an analysis of the effects of altering the current rule curve by shifting the minimum reservoir level to an earlier period and using irrigation supply and hydropower reliability as initial criteria for performance evaluation. The outcome of this analysis was a proposed rule curve, which resulted in the highest reliability for irrigation supply and hydropower generation. The third part of the research was to test the proposed rule curve under historical and future boundary conditions of inflow and demand based on the RRV criteria for the three objectives. The WEAP model was applied again to test the proposed rule curve. Two WEAP models were developed, one with the current operations rule (CR) and the other with the proposed operations rule (PR). Each model was analyzed for (i) a historical period (June 1976 to December 2013) with historical conditions of climate (inflow) and irrigation demand and (ii) for a future period with projected climate and demand conditions, based on a stress analysis of historical conditions, where the conditions varied from an increase of $90 \%$ to decrease of $90 \%$ of the historical values $[34,35]$. The evaluation of the proposed rule curve was based on performance improvement in terms of RRV under the proposed operations compared to current operations for both historical and future conditions.

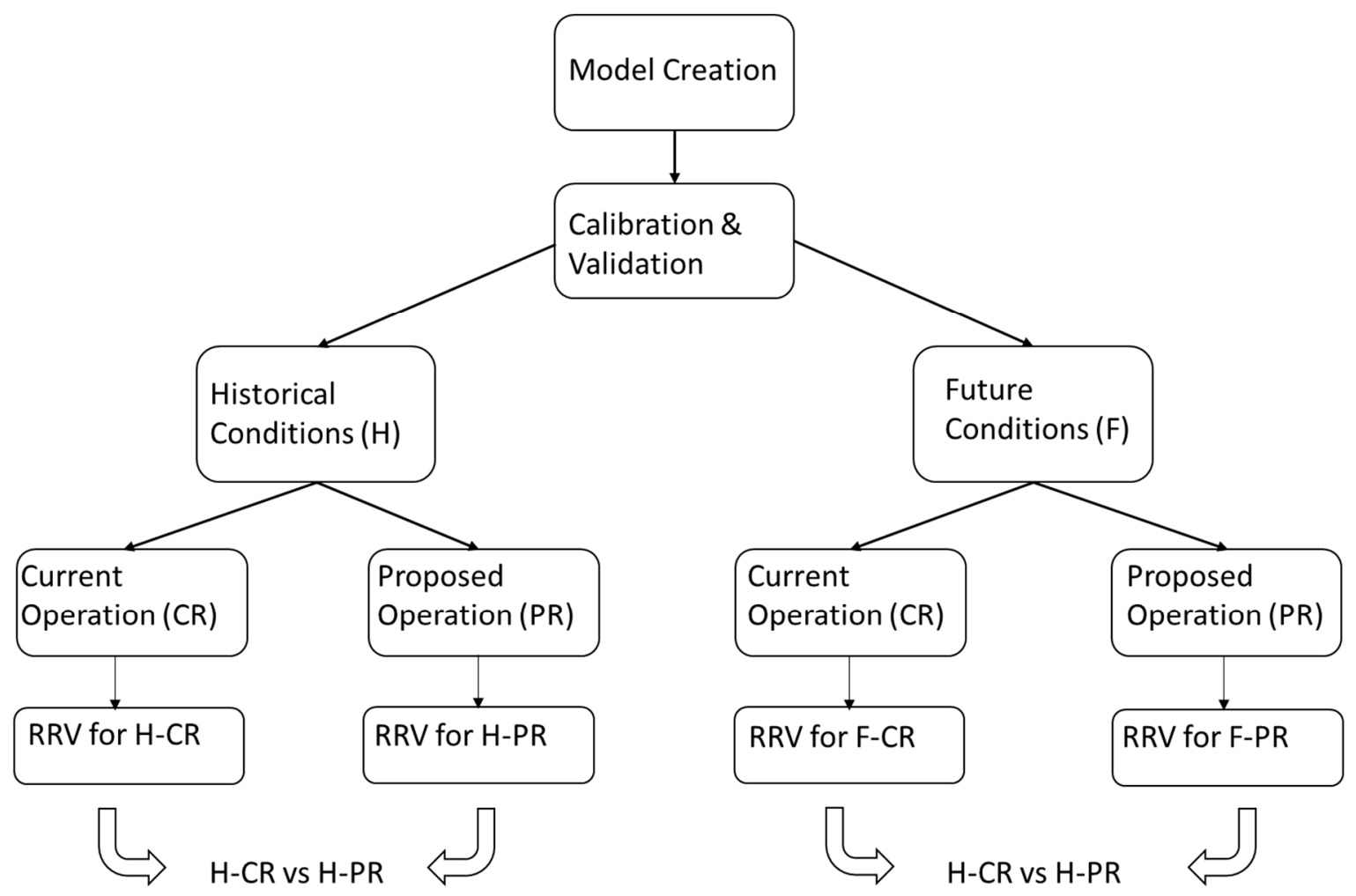

Figure 4. Flow chart representing overview of methodology.

\subsection{Water Evaluation and Planning (WEAP) System Model}

WEAP is a decision support system that integrates and simulates surface and groundwater resources. It is built on water balance principles and can access supply and demand conditions with various alternative scenarios such as climate, land use, infrastructure, and water management priorities [36]. For the present study, a representative model was created for Tarbela Dam and Reservoir using WEAP. 


\subsection{Data Collection and Input}

The daily inflow, demand, and physical data for reservoir inflow and release measurements were obtained from WAPDA, the operating authority of the Tarbela Reservoir [14]. The data range covers the period from June 1976 to December 2013. The quality of data acquired from WAPDA was divided into three categories: verified, acceptable, and uncertain. The verified data refer to recorded, documented, and verified data managed by WAPDA. The acceptable quality of data was recorded and documented but not verified, and the uncertain quality of data refers to data not documented or verified by WAPDA. As the WEAP model of Tarbela is demand-driven, it was very important to have accurate inflow, demand, and physical data of the reservoir [37]. The daily inflow and demand data were of verified quality. The physical data for the reservoir were mainly of verified quality, except evaporation, which was of acceptable quality. Tarbela Dam and Reservoir were modeled by describing the physical, operation, hydropower, cost, and priority in WEAP. The WEAP model was calibrated based on the comparison of the observed releases to the WEAP model releases. The calibration period from June 1976 to December 2001 was selected as a representative record of the entire 1976 to 2013 simulation period, considering mean annual flow and extreme events (Figure 5a). Nash-Sutcliffe efficiency (NSE) was used to calculate the accuracy of the observed data and model data [38]. A NSE value close to 1 shows that the accuracy of the model is high. The time series of the releases from the model with the increase in the evaporation by $30 \%(0.026 \mathrm{ft} / \mathrm{day})$ resulted in the highest NSE index of 0.77 . Therefore, a $30 \%$ increase in evaporation was selected as the chosen value for calibration. The timing of the model peaks matched well with the observed discharge values. However, the magnitude of the peak values was higher than the observed discharge values. The validation period was selected as January 2002 to December 2013. The validation results gave an NSE index value of 0.74 (Figure 5b).

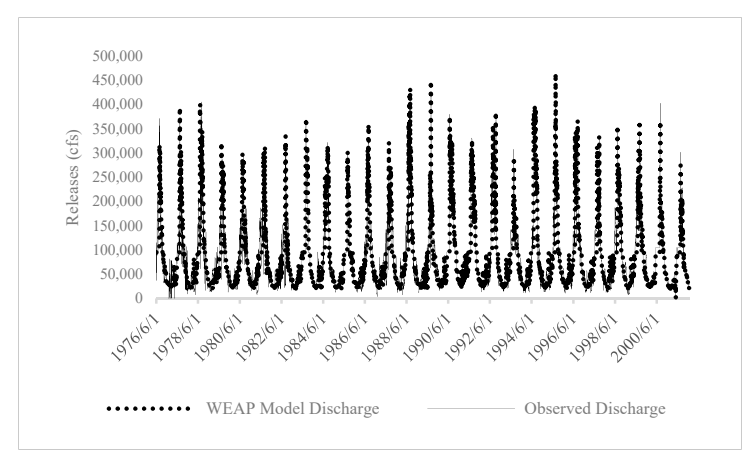

(a)

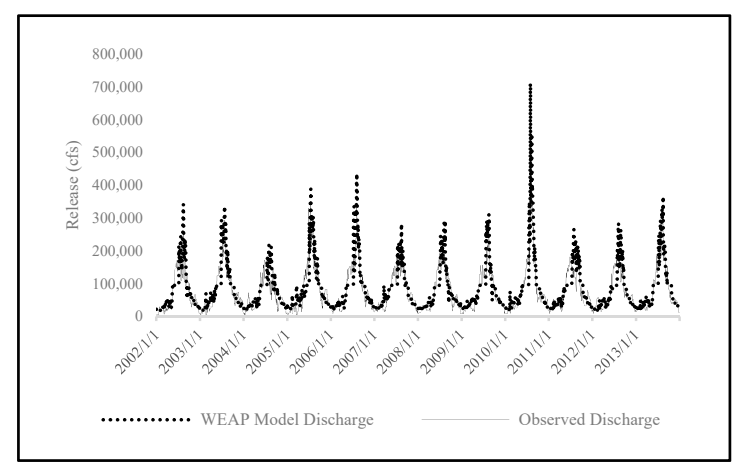

(b)

Figure 5. Hydrographs of the observed and simulated releases showing (a) calibrated model fit and (b) validation period.

\subsection{Exploration of Altered Reservoir Operations}

The altered operations of Tarbela Dam were developed by changing the target water surface elevations in the reservoir (i.e., the rule curve) with the intent of improving the performance under historical and future conditions. The altered operations to explore were guided by the following observations of current operations:

(1) Under current operations, the water level in the reservoir is maintained at the minimum from mid-May to mid-June. By maintaining the reservoir water surface level at the minimum, the water releases are maximized, but at the expense of hydropower generation potential. The releases should also be maximized in earlier months to better complement irrigation demands. Therefore, one proposed operation change is to adjust the timing of the minimum reservoir level by shifting it to an earlier period. The rule curve can thus be modified but adhere to three constraints. First, the maximum reservoir level should be targeted for late August because of high 
flows during July and August. Second, the proposed earlier drawdown of the reservoir must follow the water indent requirements from the provinces which are based on crop water demand. Third, drawdown and filling rate should not exceed $3 \mathrm{~m} /$ day to ensure the structural integrity of the dam. Figure 6 shows the resulting set of rule curves with varying minimum reservoir levels. Using WEAP simulations, the recommended rule curve (herein called proposed operations) can be set based on the best tradeoff for reliability between irrigation and hydropower objectives.

(2) Since flood control is not addressed by the proposed changes in the timing of the minimum water level or other changes in the rule curve, structural changes to upgrade the capacity of the tunnels (increasing maximum hydraulic outflow) were investigated as a solution.

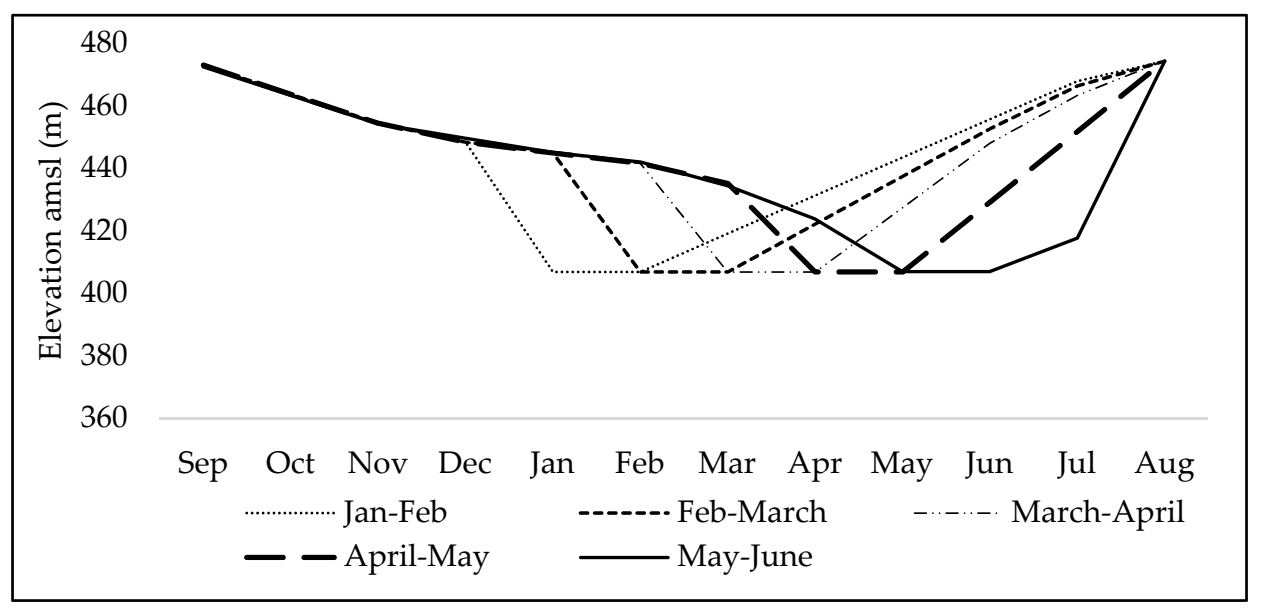

Figure 6. Rule curves with different periods of minimum reservoir levels.

\subsection{Performance Evaluation of Proposed Operations}

Following Hashimoto et al., (1982), the performance evaluation (RRV of each objective) of the proposed operations was based on comparing current operations and proposed operations under historical and future climate (inflow) and irrigation demand: current operations (CR) vs. proposed operations (PR) under historical climate and demand conditions (H) (H-CR vs. H-PR) and current operations vs. proposed operations under future climate and demand conditions (F) (F-CR vs. F-PR) [39]. The future conditions refer to projected inflow and irrigation water demand conditions based upon the stress test on historical conditions. The period for the future conditions was from January 2014 to December 2050. The number of years in the future was the same as that used for the historical conditions because the future conditions were not precisely calculated but assumed as varying ranges between $-90 \%$ to $90 \%$ (10\% interval) of the historical conditions. Based on previous studies, this range of future conditions is plausible to represent the extreme conditions, i.e., extensive floods and long-term droughts and very high and low irrigation water demands [40].

Three performance indices, viz. reliability, resilience, and vulnerability, were used for performance evaluation.

Reliability is defined as the probability that the system status remains in a satisfactory state. Water for irrigation supply and hydropower generation reliability for each scenario were calculated internally in WEAP. WEAP calculates reliability as:

$$
\text { Reliability }(R t)=\frac{\text { Number of time periods of zero shortage }(Z t)}{\text { Total Time Period }(T p)}
$$

where, $0 \leq R t \leq 100, \mathrm{Zt} \leq \mathrm{Tp}$.

For water supply and hydropower reliability, the time period of zero shortage means a sufficient volume of water was supplied to the demand node and the turbines for hydropower generation. 
The flood control reliability was externally calculated based on the same definition of reliability as used for water supply and hydropower. For flood control reliability, the time period of zero shortage refers to the days when the releases from the reservoir were less than $11,326 \mathrm{~m}^{3} / \mathrm{s}$.

Resilience describes how quickly a system recovers from the failure state after a failure occurs. The irrigation supply and hydropower generation resilience were calculated externally by exporting the supply delivered and hydropower generation data from the Result view in WEAP. The actual irrigation demand and hydropower demand and the exported Excel sheets of supply delivered and hydropower generation were used to determine the number of times the system follows a failure state $(F)$ from the satisfactory state $(\mathrm{S})$ and a number of days the system was in the failure state (Tf). The failure state was defined as when the required volume of water could not be released from the reservoir for irrigation demand or hydropower generation. The frequency of a satisfactory state following an unsatisfactory state is the basis of resilience:

$$
\text { Resilience }=\frac{\text { Number of times a satisfactory state follows an unsatisfactory state }(S \rightarrow F)}{\text { Number of unsatisfactory value occurs }}
$$

The flood control resiliency was calculated externally by exporting the reservoir release data from WEAP. The number of times a satisfactory state (release less than $11,326 \mathrm{~m}^{3} / \mathrm{s}$ ) followed an unsatisfactory state (number of times when the flow exceeded 11,326 $\mathrm{m}^{3} / \mathrm{s}$ ) and the number of days' releases exceeding the threshold values were calculated and used in the above equation.

Vulnerability refers to the likelihood of failure. The vulnerability of irrigation supply, hydropower generation, and flood control was calculated externally by using the following equation:

$$
\text { Vulnerability }=\frac{\text { Sum of Positive values of }(\text { target }- \text { delivery })}{\text { Number of times an unsatisfactory value occurs }}
$$

The performance evaluation for the entire period with proposed operations over the current operations was calculated as the percentage improvement in the system performance for each objective with proposed operations.

Percentage improvement in performance with proposed operations for any objective was computed based on Equation (4).

$$
\% \text { improvement }=\frac{\left({ }^{\prime} H-P R^{\prime} R e l\right)-\left({ }^{\prime} H-C R^{\prime} R e l\right)}{H-P R} * 100
$$

Positive values show improvement, while negative values show a decrease in the performance indices of the objective. The above equation can be substituted for future scenarios (F-CR vs. F-PR) and performance measures (resiliency and vulnerability).

\section{Results and Discussion}

\subsection{Evaluation of Altered Reservoir Operations}

The simulations of the WEAP model with altered rule curves under the historical conditions showed that the reliability of hydropower and irrigation supply was sensitive to the changes in the minimum reservoir level (Figure 7). The best combination of hydropower generation and meeting irrigation demand reliability occurred when the minimum reservoir level was set during April through May (Figure 7). This was because the minimum reservoir level in April-May increased the releases and complemented the irrigation demand pattern. Furthermore, early filling (after mid-May) resulted in more available head during the months (June-August) having the highest hydropower demand. Thus, a rule curve presented in Figure 8 was proposed for the integrated performance of the Tarbela Reservoir. 


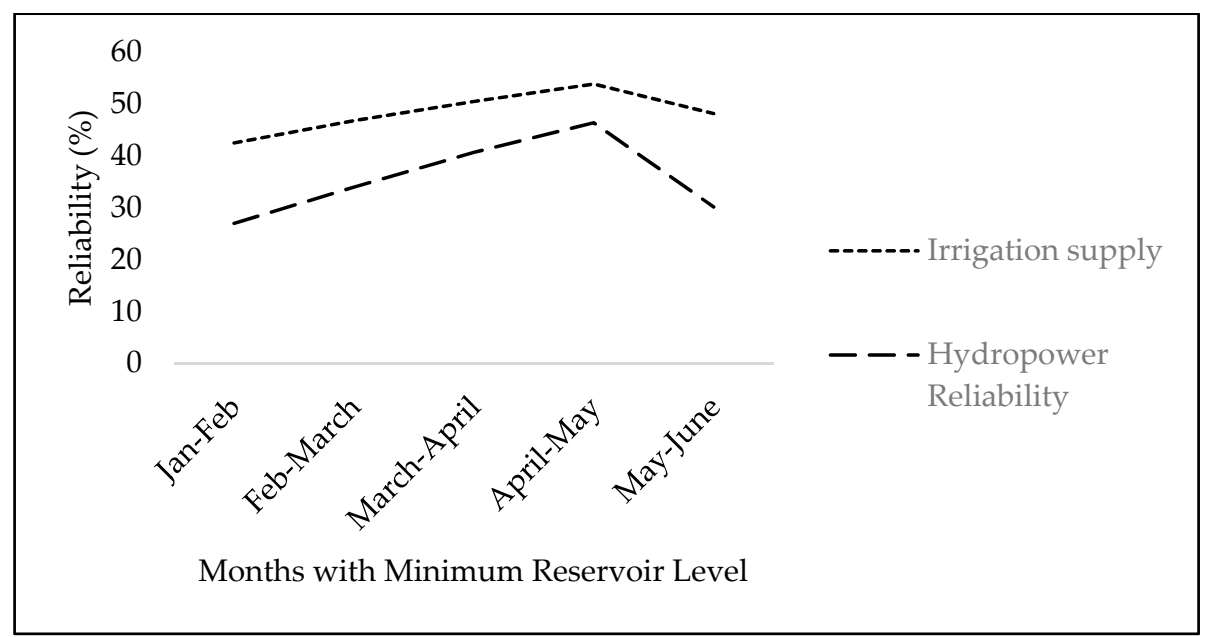

Figure 7. Reliability of irrigation supply and hydropower generation by altering the minimum reservoir level.

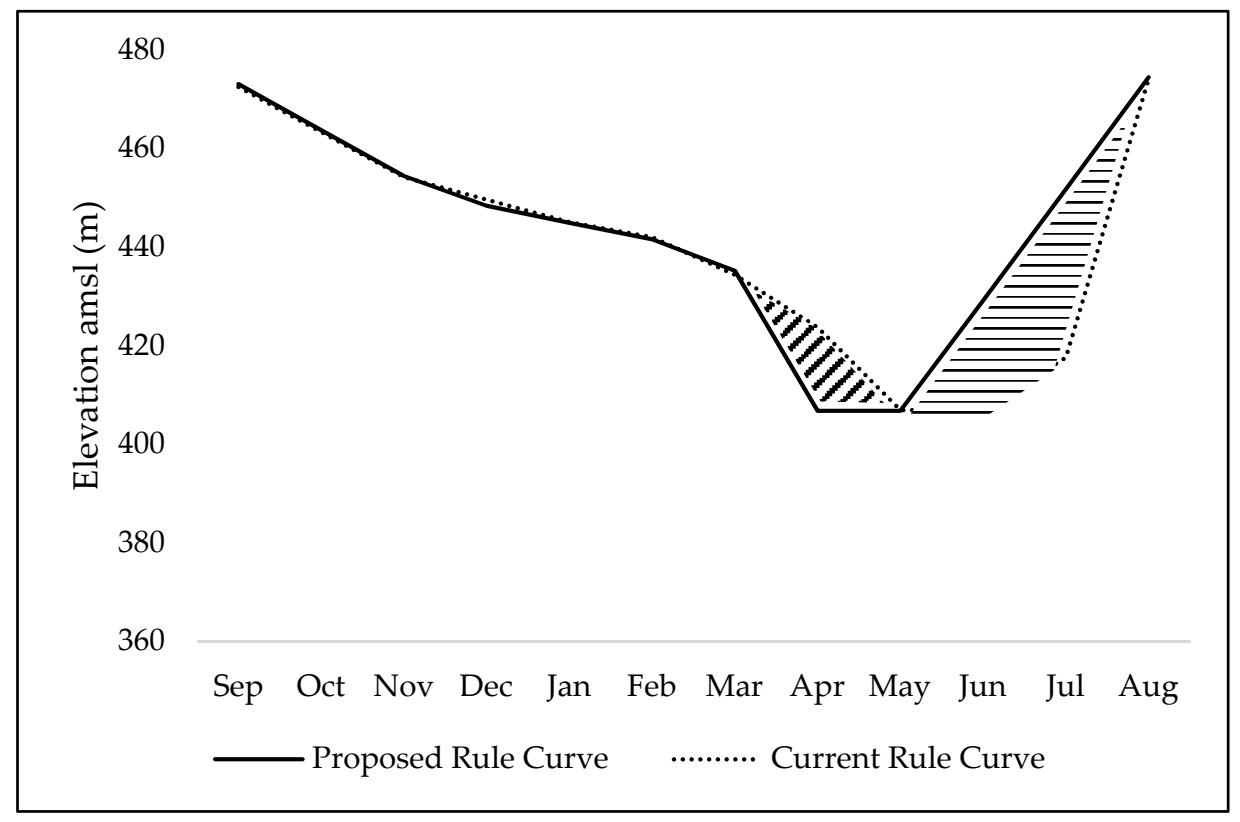

Figure 8. Proposed rule curve of Tarbela showing two distinct regions of irrigation supply improvement (inclined dashes) and hydropower generation improvement (horizontal lines).

The improvement in flood control reliability required structural changes in the outflow capacity of the dam, as the altered operations could not substantially address flooding downstream of Tarbela because of the low storage coefficient. The analysis showed that the lowest outlet capacity resulted in the lowest of flood control reliability and vice versa. The flood control reliability was maximum when the release capacity from the reservoir was $11,326 \mathrm{~m}^{3} / \mathrm{s}$ (Figure 9).

Although the difference in the percentage of flood control reliability is a fraction of a percent, this small value represents a flood occurring and causing millions of dollars' worth of damage and lost economic productivity [35]. 


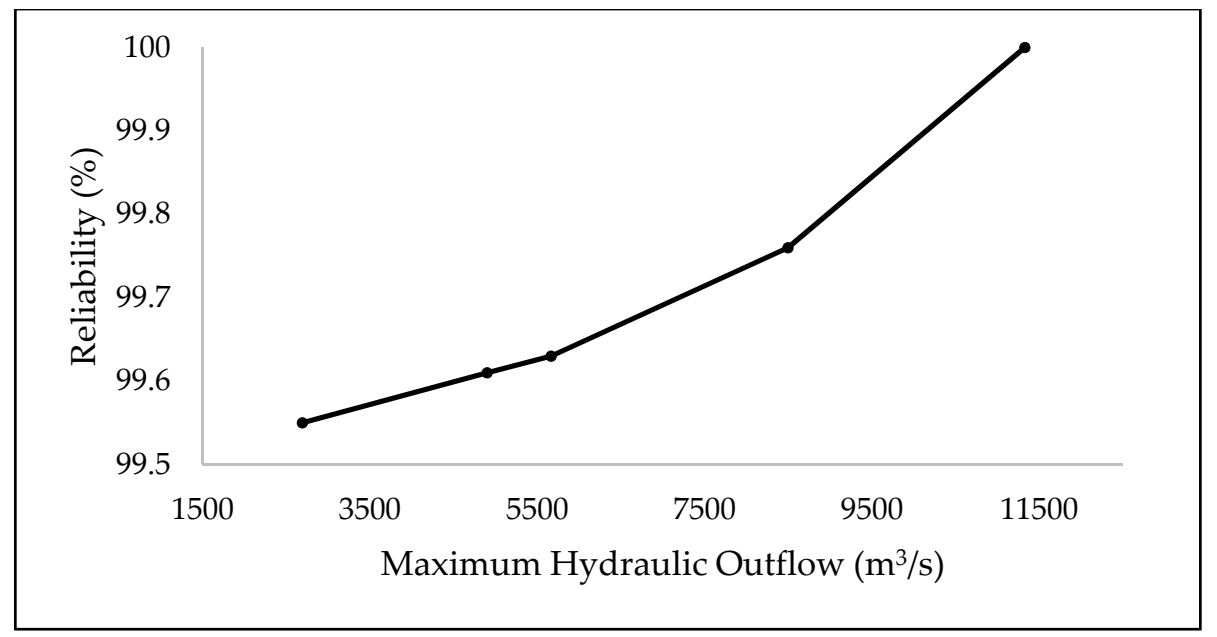

Figure 9. Percentage change in flood control reliability with changes in hydraulic flow.

\subsection{Performance Improvement with Proposed Operations for Historical and Future Conditions}

\subsubsection{Historical Conditions ( $\mathrm{H}-\mathrm{CR}$ vs. H-PR)}

The measure of improvement (RRV) for the three objectives for the period of the analysis is presented as the cumulative distribution function for each performance measure (Figure 10a,b). The likelihood of occurrence of higher reliability and resilience increases towards the right and when the curve follows a narrow band as with PR. Based on the cumulative distribution frequency (CDF) curves, the improvement in the system performance is summarized as a $3 \times 3$ matrix with three objectives and three performance measures, as shown in Table 2.

Table 2. Percentage increase in reliability, resilience, and vulnerability (RRV) with proposed operations for historical conditions.

\begin{tabular}{cccc}
\hline Objectives & Reliability & Resilience & Vulnerability \\
\hline Water Supply & $17^{*}$ & $67^{*}$ & 7 \\
Hydropower Generation & $34^{*}$ & $346^{*}$ & $22^{*}$ \\
Flood Control & $0.3^{*}$ & - & -
\end{tabular}

* Statistically significant difference at $95 \%$ confidence level based on two sample $t$-test using proposed rule curve of Tarbela compared to the current rule curve.

The water supply and hydropower objectives show improvement in terms of reliability and resilience, but this improvement renders the system more vulnerable. The tradeoffs between the RRV criteria have been analyzed by past researchers $[18,28,41]$. It was demonstrated that if the system reliability is increased and/or maximum length of consecutive deficits decrease, the vulnerability of the system to large deficits increases. For Tarbela Reservoir, the reduced uncertainty and increased reliability and resilience for irrigation supply and hydropower were achieved by restricting releases to the outlet structures (after passing through the hydropower turbines) instead of spillways. In addition, the raising of the water level during the wet season and shifting of the minimum reservoir level to April-May increased the volume of water available for hydropower generation and irrigation water supply, respectively. The flood control objective shows a minor improvement in reliability. Because of the lack of failure in terms of flood, resilience and vulnerability could not be calculated. 


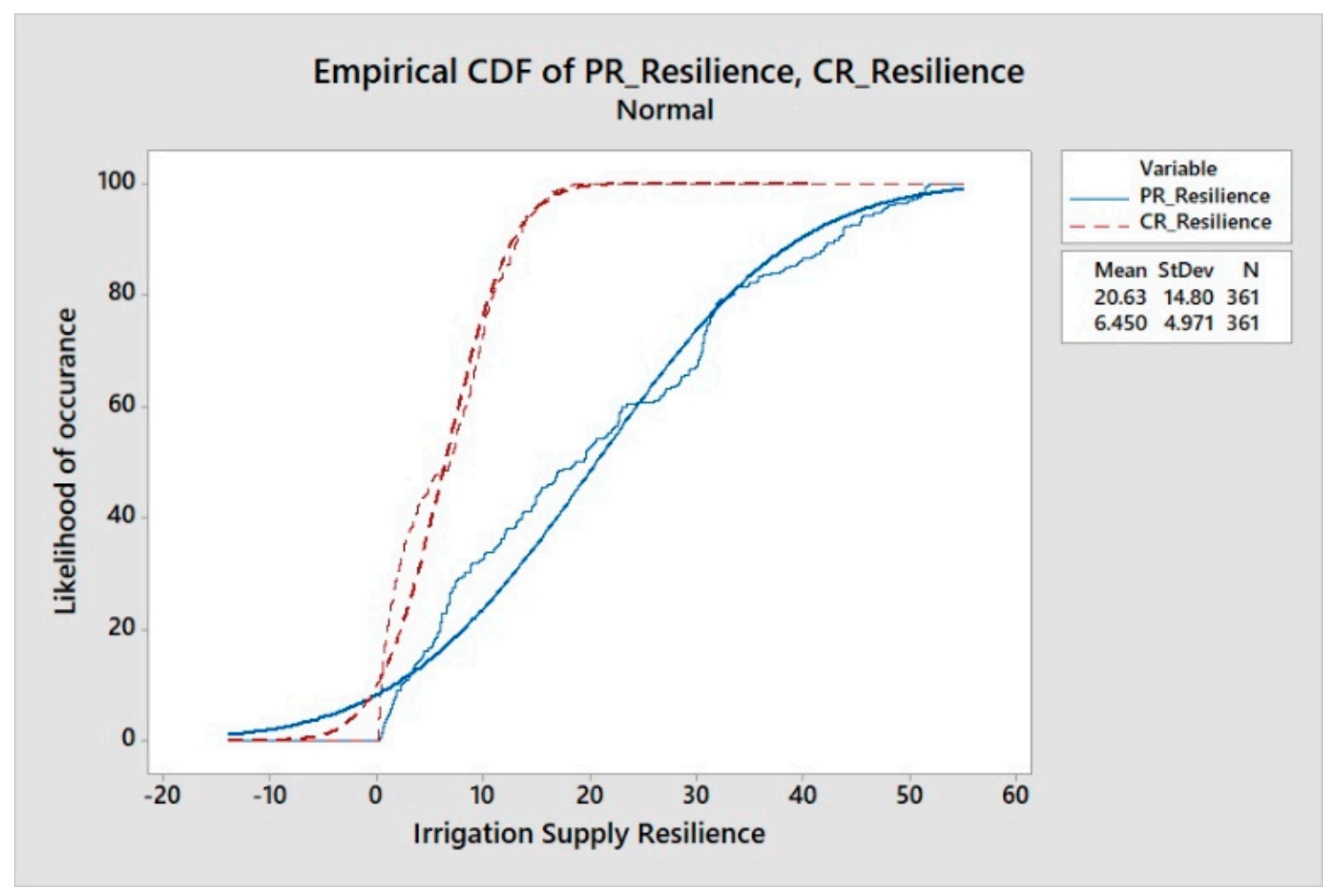

(a)

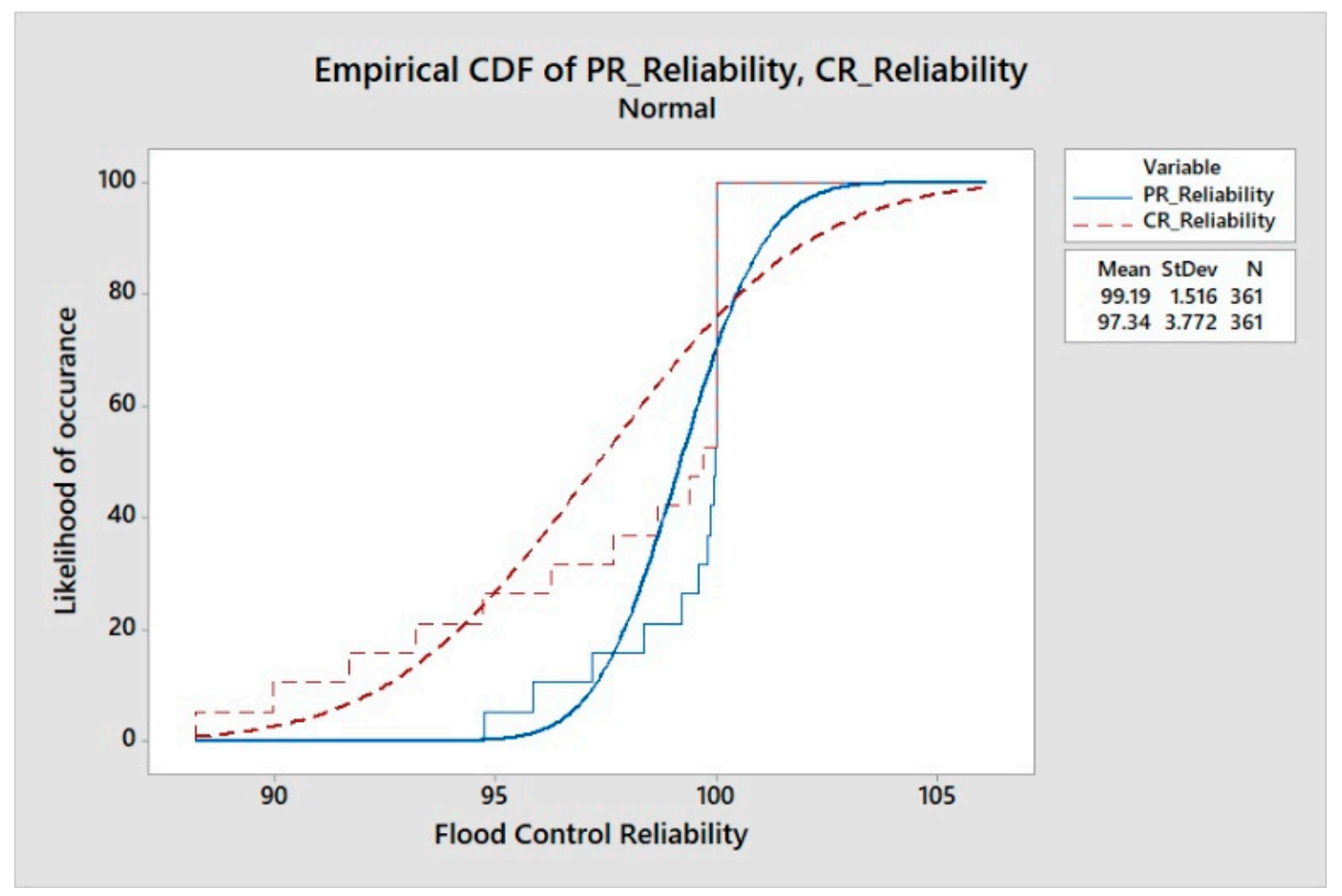

(b)

Figure 10. The plot of cumulative distribution frequency (CDF) of objectives (a) irrigation supply resilience and (b) flood control. 


\subsubsection{Future Conditions (F-CR vs. F-PR)}

The system response to future demand and climate conditions with current and proposed operations was analyzed by developing contour graphs for each objective and performance measure (Figure 11a,b and Figure 12a,b). The contour graphs were developed with the ranges of climate-induced inflow changes on the $y$-axis and demand changes on the $x$-axis. They provide a framework for determining the system response under a specific future demand and climate condition.

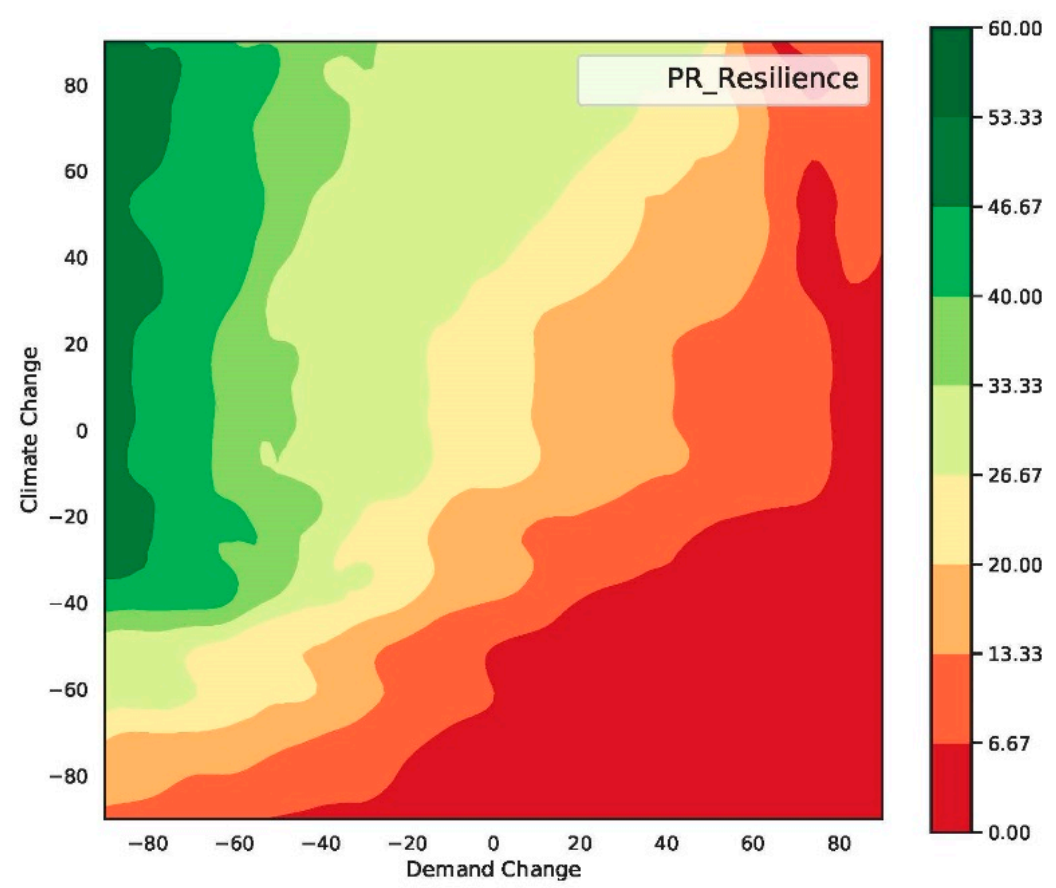

(a)

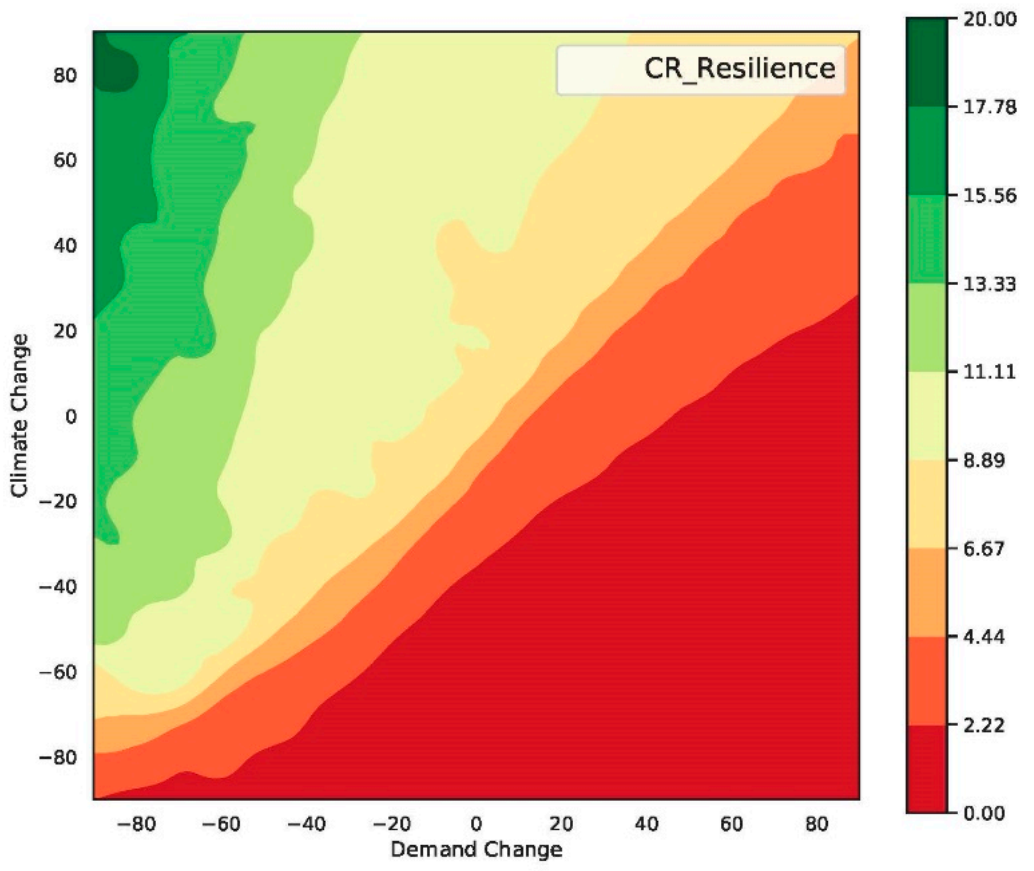

(b)

Figure 11. Contour graphs of resilience for the irrigation supply objective (a) proposed, (b) current operations. 


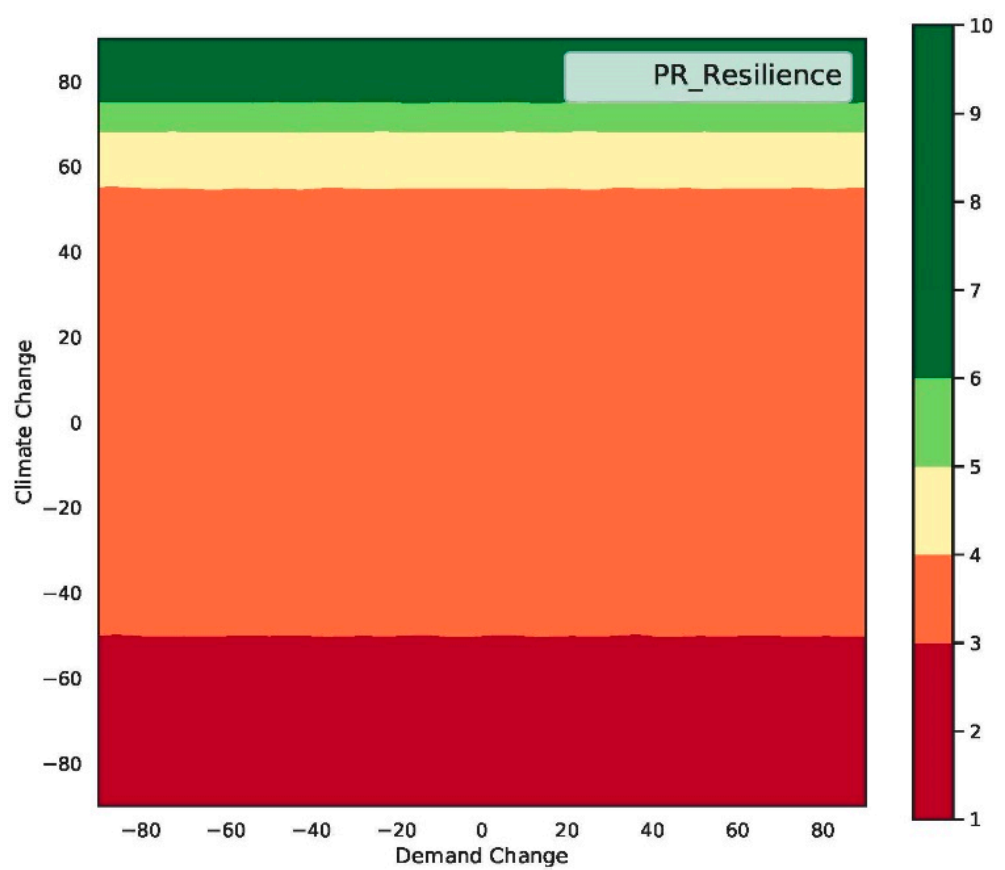

(a)

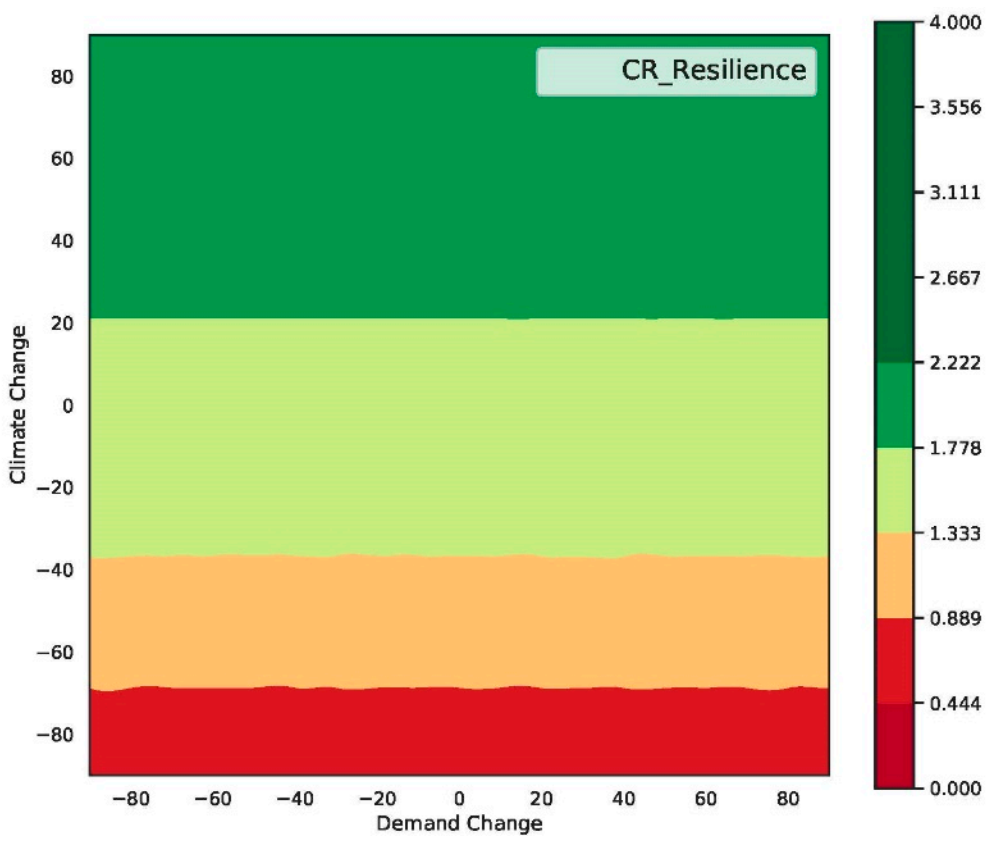

(b)

Figure 12. Contour graphs of resilience for the hydropower generation objective (a) proposed, (b) current operations.

The three objectives of water supply, hydropower generation, and flood control exhibited distinct behavior in terms of their respective sensitivities to inflow and demand variations. The RRV for irrigation water supply was very sensitive to the changes in inflow and downstream demands. The response for irrigation supply can be attributed to the fact that meeting downstream demand was dependent and coupled to the variation in inflows and inflow-demand relationship. On the other hand, the RRV for hydropower generation and flood control was not found to be sensitive to the changes in the downstream irrigation demand for a given inflow condition. This is because 
hydropower generation and flood control require constraining the water and altering the releases from the dam. Storage of water in the reservoir is dependent on the energy requirement, without any linkage to the downstream demands, and sensitive to the variation in the inflows only [42-44]. In terms of performance, the system showed the highest improvement in the resilience metric as shown in Table 3.

Table 3. Percentage increase in RRV with proposed operations for future conditions.

\begin{tabular}{cccc}
\hline Objectives & Reliability & Resilience & Vulnerability \\
\hline Water Supply & 7 & $219^{*}$ & 11 \\
Hydropower Generation & $19 *$ & $136^{*}$ & 13 \\
Flood Control & $2 *$ & $-33^{*}$ & $-39 *$ \\
* Statistically significant difference at $95 \%$ confidence level based on two-sample $t$-test.
\end{tabular}

The contour maps developed for the future conditions provide a range of system responses in terms of RRV from which system response for any plausible future scenarioasin (UIB) from $-15 \%$ can be determined. For instance, Lutz et al., (2014) suggested a range of future inflow variability in the upper Indus b to $60 \%$, with respect to historical time series from 1971-2000, by the end of 21st century [22]. Similarly, Amin et al., (2018) determined future increase in irrigation demand by $50 \%$ in the UIB in 2050 compared to 2010 [45]. From Figure 11, decreases in inflow by 15\% and increase in demand by $50 \%$ shows that the irrigation supply resilience will be around $14 \%$ for PR and $4 \%$ for CR. The contour maps are useful to examine system response across a range of what-if conditions.

\section{Conclusions and Recommendations}

In this study, a WEAP model for the Tarbela Reservoir was created and used to analyze integrated performance for historical and future scenarios against multiple objectives and multiple criteria. The limitations of the current operations of Tarbela Dam were explored, and a possible new operations approach was identified. The methodology of quantifying the improvement under proposed operations was based on computing the RRV of each objective (irrigation demand, hydropower generation, flood control) under the current operation strategy and the proposed altered operation strategy, for both historical and future climate and demand conditions. The RRV of respective operations and conditions combinations were computed and examined to determine if improvements could be achieved.

The main conclusions from the research are as follows:

(1) Effects of rule curve change on reservoir performance: The timing of the minimum target water elevation in Tarbela Reservoir was shifted one month earlier in the calendar year to April-May. The shifting of the minimum reservoir level increased the performance of Tarbela Reservoir for both irrigation supply and hydropower objectives. This shifting of the rule curve will ensure an increase in sustainability and resilience to future uncertainties of climate and irrigation and hydropower demand.

(2) Maximum hydraulic outflow: The maximum hydraulic outflow played a pivotal role in controlling the flooding downstream of Tarbela. It was concluded that the maximum release capacity from the tunnels needs to be increased to reduce spillway discharges that do not generate hydropower. The downstream channel of Tarbela can safely convey $11,326 \mathrm{~m}^{3} / \mathrm{s}$, which was tested and shown to lead to improved performance.

(3) Percentage improvement in RRV with proposed operations: The performance of the reservoir operations with proposed operations over current operations was evaluated for the entire period for historical and future climate and demand conditions. The analysis resulted in the exploration of gains in objectives with the proposed operations. The performance evaluations of water supply for irrigation and hydropower objectives showed improvement in reliability and resilience with an increase in vulnerability. The flood control objective resulted in an increase in reliability and a decrease in resilience and vulnerability. 


\section{Future Work and Limitations of Study}

The limitations with the existing model are that the future climate and demand conditions were not forecasted. They were based on arbitrary percentage increases and decreases of the historical climate and inflow observations. Although simplified, the approach does provide a reasonable stress test of the system that is useful for evaluating proposed changes under uncertain moderate and extreme conditions, giving confidence to decision making.

The improvement in the performance measures was only evaluated as the percentage increase or decrease of meeting objectives compared with current operations. This approach does not consider the tangible benefits such as cost/profit per unit release of water from the reservoir. This should be investigated as part of future work to confirm the conclusions drawn from determining the performance improvements.

Another uncertain factor not considered in this study was the change in live storage volume due to sedimentation and possible future upstream dam construction (especially Diamir Bhasha Dam). These factors could impact the storage volume required to meet the objectives, which could affect the system performance in terms of RRV. Additional alterations in operations may be needed.

Finally, the approach of using simulation to investigate selected operation alterations could be refined to include optimization. The investigation was thorough; therefore, optimization is not expected to significantly alter the results. However, as the solution space and constraints are made more complicated, optimization may be needed.

Author Contributions: Conceptualization and methodology, A.R., and S.B.; resources and data acquisition, R.B.; and D.H.; writing-original draft preparation, A.R.; writing-review and editing, A.R., S.B., and D.H.; visualization, A.R., S.B., R.B., and D.H.; supervision, S.B. All authors have read and agreed to the published version of the manuscript.

Funding: This research was funded by the United States Agency for International Development through a U.S,-Pakistan Center for Advanced Studies in Water (University of Utah).

Acknowledgments: The authors are sincerely grateful to WAPDA for data and technical help and two anonymous reviewers for their suggestions to improve the quality of manuscript.

Conflicts of Interest: The authors declare no conflict of interest.

Disclaimer: This study was made possible by the support of the United States Government and the American people through the United States Agency for International Development (USAID). The contents are the sole responsibility of the authors and do not necessarily reflect the views of USAID or the United States Government.

\section{References}

1. Pereira, L.S.; Oweis, T.; Zairi, A. Irrigation management under water scarcity. Agric. Water Manag. 2002, 57, 175-206. [CrossRef]

2. Somlyódy, L.; Varis, O. Freshwater under pressure. Int. Rev. Environ. Str. 2006, 6, 181-204.

3. Wheater, H.; Evans, E. Land use, water management and future flood risk. Land Use Policy 2009, 26, S251-S264. [CrossRef]

4. Kijne, J.W. Lessons learned from the change from supply to demand water management in irrigated agriculture: A case study from Pakistan. Water Policy 2001, 3, 109-123. [CrossRef]

5. Qureshi, A.S.; McCornick, P.G.; Sarwar, A.; Sharma, B.R. Challenges and prospects of sustainable groundwater management in the Indus Basin, Pakistan. Water Resour. Manag. 2010, 24, 1551-1569. [CrossRef]

6. Arfan, M.; Lund, J.; Hassan, D.; Saleem, M.; Ahmed, A. Erratum: Assessment of spatial and temporal flow variability of the Indus River. Resources 2019, 8, 103. [CrossRef]

7. Hassan, D.; Rais, M.N.; Ahmed, W.; Bano, R.; Burian, S.J.; Ijaz, M.W.; Bhatti, F.A. Future water demand modeling using water evaluation and planning: A case study of the Indus basin in Pakistan. Sustain. Water Resour. Manag 2019, 5, 1903-1915. [CrossRef]

8. Kirsch, T.D.; Wadhwani, C.; Sauer, L.; Doocy, S.; Catlett, C. Impact of the 2010 Pakistan floods on rural and urban populations at six months. PLoS Curr. 2012, 4, 4fdfb212d2432. [CrossRef]

9. Looney, R. Economic impacts of the floods in Pakistan. Contemp. South Asia 2012, 20, 225-241. [CrossRef] 
10. Tate, E.L.; Farquharson, F.A. Simulating reservoir management under the threat of sedimentation: The case of Tarbela dam on the river Indus. Water Resour. Manag. 2000, 14, 191-208. [CrossRef]

11. Khan, N.M.; Tingsanchali, T. Optimization and simulation of reservoir operation with sediment evacuation: A case study of the Tarbela Dam, Pakistan. Hydrol. Process. Int. J. 2009, 23, 730-747. [CrossRef]

12. Tarar, R.N. Performance of Tarbela Dam project. In In Proceedings of Pakistan Engineering Congress, 69th Annual Session Proceedings Report; Punjab, Pakistan, 2006; pp. 8-10. Available online: https://www.pecongress.org. pk/images/upload/books/632.pdf (accessed on 30 August 2020).

13. Water \& Power Development Authority. Available online: http://www.wapda.gov.pk/index.php/investor-scorner/annual-report (accessed on 24 April 2018).

14. The World Commission on Dams. Available online: https://energypedia.info/wiki/World_Commission_on_ Dams_(WCD)_Report (accessed on 27 April 2018).

15. Khan, N.M.; Babel, M.S.; Tingsanchali, T.; Clemente, R.S.; Luong, H.T. Reservoir optimization-simulation with a sediment evacuation model to minimize irrigation deficits. Water Resour. Manag. 2012, 26, 3173-3193. [CrossRef]

16. Naheed, G.; Mahmood, A. Water requirement of wheat crop in Pakistan. Pak. J. Meteorol. 2009, 6, 89-97.

17. Naheed, G.; Rasul, G. Projections of crop water requirement in Pakistan under global warming. Pak. J. Meteorol. 2010, 7, 45-51.

18. Moy, W.S.; Cohon, J.L.; Revelle, C.S. A programming-model for analysis of the reliability, resilience, and vulnerability of a water-supply reservoir. Water Resour. Res. 1986, 22, 489-498. [CrossRef]

19. Vogel, R.M.; Bolognese, R.A. Storage-reliability-resilience-yield relations for over-year water-supply systems. Water Resour. Res. 1995, 31, 645-654. [CrossRef]

20. Jain, S.K.; Bhunya, P.K. Reliability, resilience and vulnerability of a multipurpose storage reservoir/confiance, résilience et vulnérabilité dun barrage multi-objectifs. Hydrol. Sci. J. 2008, 53, 434-447. [CrossRef]

21. Mateus, M.C.; Tullos, D. Reliability, sensitivity, and vulnerability of reservoir operations under climate change. J. Water Resour. Plan. Manag. 2017, 143, 04016085. [CrossRef]

22. Lutz, A.F.; Immerzeel, W.W.; Shrestha, A.B.; Bierkens, M.F.P. Consistent increase in high Asia's runoff due to increasing glacier melt and precipitation. Nat. Clim. Chang. 2014, 4, 587-592. [CrossRef]

23. Wang, W.; Xiang, Y.; Gao, Y.; Lu, A.; Yao, T. Rapid expansion of glacial lakes caused by climate and glacier retreat in the central Himalayas. Hydrol. Process. 2015, 29, 859-874. [CrossRef]

24. Khan, A.J.; Koch, M. Selecting and downscaling a Set of climate models for projecting climatic change for impact assessment in the upper Indus basin (UIB). Climate 2018, 6, 89. [CrossRef]

25. Yu, W.; Yang, Y.-C.; Savitsky, A.; Alford, D.; Brown, C.; Wescoat, J.; Debowicz, D.; Robinson, S. The Indus Basin of Pakistan: The Impacts of Climate Risks on Water and Agriculture; The World Bank: Washington, DC, USA, 2013.

26. Hunt, J.R.; Lilley, J.M.; Trevaskis, B.; Flohr, B.M.; Peake, A.; Fletcher, A.; Zwart, A.B.; Gobbett, D.; Kirkegaard, J.A. Early sowing systems can boost Australian wheat yields despite recent climate change. Nat. Clim. Chang. 2019, 9, 244-247. [CrossRef]

27. Rashid, M.; Haider, S.; Latif, M.; Raja, N. Multi-objective optimization for irrigation deficit through cascade'reservoirs. Eur. Water 2017, 59, 323-329.

28. Kindler, J.; Tyszewski, S. Multicriteria evaluation of decision rules in the design of a storage reservoir. System analysis for water resources management: Closing the gap between the theory and practice. In Proceedings of the Baltimore Symposium, Baltimore, MD, USA, 19-22 May 1989.

29. Kim, U.; Kaluarachchi, J.J. Climate change impacts on water resources in the upper blue Nile river basin, ethiopia 1. JAWRA J. Am. Water Resour. Assoc. 2009, 45, 1361-1378. [CrossRef]

30. Khan, A.; Richards, K.S.; Parker, G.T.; McRobie, A.; Mukhopadhyay, B. How large is the upper Indus basin? The pitfalls of auto-delineation using DEMs. J. Hydrol. 2014, 509, 442-453. [CrossRef]

31. Mukhopadhyay, B.; Khan, A. A quantitative assessment of the genetic sources of the hydrologic flow regimes in upper Indus basin and its significance in a changing climate. J. Hydrol. 2014, 509, 549-572. [CrossRef]

32. Cook, E.R.; Palmer, J.G.; Ahmed, M.; Woodhouse, C.A.; Fenwick, P.; Zafar, M.U.; Wahab, M.; Khan, N. Five centuries of upper Indus river flow from tree rings. J Hydrol 2013, 486, 365-375. [CrossRef]

33. Tariq, S.M. Pakistan-India Relations: Implementation of Indus-Water Treaty-A Pakistani Narrative; The Pakistan Institute of Legislative Development and Transparency (PILDAT), Office: Islamabad, Pakistan, 2010; p. 9. 
34. Ray, P.A.; Brown, C.M. Introduction. In Confronting Climate Uncertainty in Water Resources Planning and Project Design: The Decision Tree Framework; World Bank Publications: Washington, DC, USA, 2015; pp. 1-6.

35. Brown, C.; Steinschneider, S.; Ray, P.; Wi, S.; Basdekas, L.; Yates, D. Decision scaling (DS): Decision support for climate change. In Decision Making under Deep Uncertainty; Springer: Cham, Switzerland, 2019; pp. 255-287.

36. Sieber, J. WEAP water evaluation and planning system. In Proceedings of the 3rd International Congress on Environmental Modelling and Software, Burlington, VT, USA, 1 July 2006.

37. Hassan, D.; Burian, S.J.; Bano, R.; Ahmed, W.; Arfan, M.; Naseer Rais, M.; Rafique, A.; Ansari, K. An assessment of the Pakistan water apportionment accord of 1991. Resources 2019, 8, 120. [CrossRef]

38. Nash, J.E.; Sutcliffe, J.V. River flow forecasting through conceptual models part I-A discussion of principles. J. Hydrol. 1970, 10, 282-290. [CrossRef]

39. Hashimoto, T.; Stedinger, J.R.; Loucks, D.P. Reliability, resiliency, and vulnerability criteria for water-resource system performance evaluation. Water Resour. Res. 1982, 18, 14-20. [CrossRef]

40. Tariq, M.A.U.R.; Van De Giesen, N. Floods and flood management in Pakistan. Phys. Chem. Earth 2012, 48, 11-20. [CrossRef]

41. Kindler, J. The Monte Carlo approach to optimization of the operation rules for a system of storage reservoirs/la méthode Monte Carlo pour l'optimization des règles opératoires pour un système de réservoirs. Hydrol. Sci. J. 1977, 22, 203-214. [CrossRef]

42. Robinson, P.J. Climate change and hydropower generation. Int. J. Climatol. 1997, 17, 983-996. [CrossRef]

43. Harrison, G.; Whittington, H.; Wallace, A. Sensitivity of hydropower performance to climate change. Int. J. Power Energy Syst. 2006, 26, 42. [CrossRef]

44. Zeng, R.J.; Cai, X.M.; Ringler, C.; Zhu, T.J. Hydropower versus irrigation-an analysis of global patterns. Environ. Res. Lett. 2017, 12. [CrossRef]

45. Amin, A.; Iqbal, J.; Asghar, A.; Ribbe, L. Analysis of current and future water demands in the Upper Indus Basin under IPCC climate and socio-economic scenarios using a hydro-economic WEAP model. Water 2018, 10, 537. [CrossRef]

(C) 2020 by the authors. Licensee MDPI, Basel, Switzerland. This article is an open access article distributed under the terms and conditions of the Creative Commons Attribution (CC BY) license (http://creativecommons.org/licenses/by/4.0/). 